\title{
Musculoskeletal Pain among Rural Homemakers and their Health Seeking Behaviors
}

\author{
Sanjida Nawrin ${ }^{1}$ and Md Mahmudul Hasan ${ }^{2 *}$ \\ ${ }^{1}$ Master of Public Health, National Institute of Preventive and Social Medicine (NIPSOM), Bangladesh \\ ${ }^{2}$ Coordinator of Inclusive Health and Education, Bangladesh Manobadhikar Bastabayan Foundation (BMBF), Bangladesh
}

*Corresponding author: Md Mahmudul Hasan, Coordinator of Inclusive Health and Education, Bangladesh Manobadhikar Bastabayan Foundation (BMBF), Bangladesh.

\begin{abstract}
Background: Homemakers use their time \& strengths to provide service to make their house a home. This routine and compulsory household maintenance task often leads them to musculoskeletal pain (MSP).

Purpose: The aim of this study was to identify the areas of musculoskeletal pain in different parts of the body as a result of household work among rural homemakers in Bangladesh and in this case to detect their health-seeking behaviors.
\end{abstract}

Materials and Methods: Three hundred and forty one randomly selected married homemakers' living in the rural area of Barishal division of Bangladesh who has experienced any type of musculoskeletal pain at least once in life due to household work participated in this cross sectional study. Data were collected by pretested semi-structured questionnaire through face to face interview.

Results: The one year pattern of MSP among respondents were lower back (80.46\%), followed by knee (24.4\%), neck (19.13\%), upper-back (11.3\%), shoulder (5.3\%), hips/thighs (5.46\%), ankle/feet (4.8\%), wrist/hand (4.4\%), and elbow (3.4\%). Lower back pain had an association with lifting heavy objects, number of children, educational qualification, age and awkward/faulty postures $(\mathrm{p}<0.05)$. Total working experiences more than 10 years was associated with upper back pain $(\mathrm{p}<0.05)$.Further, pain in the wrist/hand and knee $(\mathrm{P}<0.05)$ was linked with awkward position and spending more than 8 hours a day doing homework. In addition, there was a relationship between repetitive work and wrist/hand pain $(\mathrm{p}<0.05)$. In contrast, three-fourth received treatment for their pain. Of these, $54.9 \%$ sought treatment from the para-professional health service providers.

'This study shows that housework exposed musculoskeletal pain on the different sites of the body. Although sufferers sought treatment in this regard, it is necessary to improve policies \& intervention for reducing possible risks of musculoskeletal pain among homemakers.

Keywords: Musculoskeletal pain; health seeking behavior; Rural homemaker

\section{Introduction}

Musculoskeletal pain is one of the modern epidemic health problems. This problem responsible for a high proportion of impairment, loss of productivity and substantial use of health and social services [1]. Several epidemiological studies have demonstrated the evidence of a causal relationship between physical exertion at work and work related musculoskeletal pain (MSP) [2]. Both professional and informal work at home or outside require physical strains that can produce musculoskeletal pain(MSP) as a result of inflammatory conditions in muscles, nerves, tendons, cartilage, spinal discs or other soft tissues. MSP is found throughout all generations, identities and social group [3]. Although previous studies suggest that prevalence rates of musculoskeletal pain were higher for women than for men [4]. WHO reported that women constitutes $42 \%$ of the global work force and they are more likely to work in the informal economy sector (domestic work, agricultural laborers, handicrafts industry, etc.) [5].This trend is common in both developed and developing countries. Middle-income counties like Hong Long and Lebanon shows that fulltime homemakers experiences MSP over the different region of the body as a result of household chores [6,7]. Homemakers in developed countries 
like Italy get MSP because of housework. [8]. In Bangladesh, women typically spend less than an hour on their self-care work; in contrast, they spend 14-20 hours a day as the main person responsible for finishing family activities [9]. A recent study in Bangladesh shows that $68.49 \%$ women reported having pain on different parts of their body during the last 12 months and $50.68 \%$ of the respondents were prevented from normal daily activities due to musculoskeletal symptom [10]. It is evident that the prevalence of low back pain is higher in rural women than urban women [11]. This study is aimed at identifying MSP in different parts of the body as a result of housework among homemakers in Bangladesh as very little is known about it so far.

In contrast, woman shows little concern about their health. Despite suffering and withdrawing from work due to domestic work, very few women seek health care in this regard in Bangladesh [12].This is due to the influence of traditional gender norms where women are forced to participate in daylong household tasks as homemaker and men (husband) act as family breadwinner. Rural women rarely report their musculoskeletal problems at the right time. This habit aggravates the situation vulnerable and leading to disorder. Full-time homemakers were $40 \%$ less likely to report musculoskeletal symptoms than working women [13]. Moreover, as living with pain for a prolonged time without stopping their household activities, they are very much prone to develop the physical disability. This study will highlight the hazards of this unpaid occupation and the health-seeking behavior of the ill-fated women engaged in it.

\section{Literature Review}

Pain can be classified based on its duration and location of body systems. If the pain stays for less than six weeks and/or between six weeks to three months and/or more than three months is called acute, sub-acute, or chronic pain respectively [14]. On the other hand, various physical and physiological regions of the body are affected by the pain. Of these, musculoskeletal region has become a public health priority as a major cause of pain and a decreased quality of life. International Association of Study of Pain (IASP) described musculoskeletal pain as a known consequence of overuse, repetitive and work-related musculoskeletal disorders [15]. Work-related disorders may evolve in the workplace due to the physical tasks with which people carry out their normal work activities. Domestic work is regarded as one of the daily activities. Studies show that women are considered as the main responsible person in the family to complete the household chores. Household activities are one of the causes of many musculoskeletal risks such as lower and upper back, spine, shoulder, wrist, neck and knee pain which can later lead to temporary and permanently disabled conditions [16]. Musculoskeletal problems of housewives not only affects them by significantly impairing their activities of daily living [17] , but also affects the other members of the family as they have to spent additional hours to complete household duties [18]. Along with individual and familial domain, housework and musculoskeletal symptoms among homemakers has relationship with social (low income) and demographic (age, education, number of children) factors $[13,19]$. In addition, the economic burden of musculoskeletal pain is ranked as second to that of cardiovascular disease [15].

Musculoskeletal complaints are, in most countries, common reasons for consulting with a physician and seeking treatment; they make up to $15 \%-20 \%$ of primary care consultations [20]. The number of annual visits to a physician in the United States for low back or neck pain exceeds USD 52 million and the estimated direct medical costs associated with these conditions surpass USD 250 billion annually [21]. Similarly, the first choice for MSP-related treatment in Lebanon was physicians, followed by pharmacists, physiotherapists, chiropractors, traditional healers, and selfmedication [1]. As opposed to, these treatments were subsequently grouped into five categories in Bangladesh namely "home remedies", "traditional methods", " para-professional" , "unqualified" and " qualified" allopath, and among these, unqualified allopath was identified as the main treatment provider by most of the rural homemakers [22]. Only after the failure of such treatment they moved to qualified physicians for modern treatment. Interestingly, they resorted to the traditional healers if this failed. Apart from this, the tendency of not to visiting any health care providers for MSP is very common among the rural homemakers of Bangladesh. Less education, low economic condition, and patriarchal gender norm is responsible for having such health-seeking behavior in Bangladesh.

\section{Materials and Methods}

This cross sectional study used a sample of 341 randomly selected married homemakers from 8 wards of 4 unions of 2 upazials of Barishal district. Wards were selected through the quasi multistage process. Inclusion criteria for homemakers were age (18-45 years), marital status (married for at least a year), and living place (within the study place for one year) and experience of any type of MSP at least once in life. Visually, hearing, cognitive and mentally impaired, and pregnant woman as well as those had history of trauma in last 12 months, taking tuberculosis drugs and trauma were excluded the study population. Prior to data collection, a standard equation was used to determine the sample size [23]. The minimum sample size to be calculated was set at 331 , but 10 more were added to adjust if any non-responded data were found during the data analysis. The study period was lasting from January, 2019 to December, 2019. The questionnaires were administered at the home of selected participants in the Barishal division through the interview by the first author. Due permission was obtained from the Upazilla Health and Family Welfare after explaining the objective of the study. A pre-test of questionnaire was conducted as soon as the research protocol was approved by the approval committee of the National Institute of Preventive and Social Medicine (NIPSOM), Bangladesh.

\section{Description of Instrument}

After necessary modification and correction, the final questionnaire included four domains to meet the study objectives. The first domain was designed for obtaining socio-demographic information (age, education, income, marital status, family type, 
number of family members and children, job experience, and income). The second domain captured information related to their household activities and additional house activities, ergonomic risk factors include force, lifting and carrying heavy loads, repetitive movements, awkward posture, total work experiences ( in years), and work hours per day. The third domain captured information on Work-related musculoskeletal disorder (WRMSDs), including site of pain by body regions, effect of WMSDs on work performance, visit to health professionals and information on medication. Prevalence of WMSDs for each body region was determined by the Nordic Musculoskeletal Questionnaire- Extended (NMQ-E) tool. The investigation covered nine body regions: neck, shoulder, upper back, elbows, wrists/hands, lower back, hips/thighs, knee, and ankle/feet. The fourth domain contained information regarding health seeking behaviors of respondents for the management of pain. The questionnaire and NMQ-E was translated into Bangla (local language).

\section{Data Analysis}

Descriptive statistics of frequency, percentage, means, medians, mode, standard deviation, tables and graphs were used to summarize the data. The association between WMSDs factors and ergonomic parameters was analyzed using the chi-square $(\chi 2)$ test. All $\mathrm{P}$ values presented are two-tailed and a P-value of $<0.05$ were considered as significant.

\section{Results}

Table 1: Location of pain on the different site of the body in a given period.

\begin{tabular}{|c|c|c|c|c|}
\hline \multirow{2}{*}{ Site of Pain } & Once in Life & Last 12 Month & Last 4 Weeks & Average \\
\cline { 2 - 5 } & Frequency (\%) & Frequency (\%) & Frequency (\%) & Frequency (\%) \\
\hline Neck & $69(20.05)$ & $66(19.96)$ & $58(17.3)$ & $64(19.13)$ \\
\hline Shoulder & $19(5.7)$ & $18(5.4)$ & $16(4.8)$ & $18(5.3)$ \\
\hline Upper Back & $39(11.6)$ & $38(11.3)$ & $11(11.0)$ & $38(11.3)$ \\
\hline Elbow & $12(3.6)$ & $11(3.3)$ & $14(4.3)$ & $11(3.4)$ \\
\hline Wrist/ Hands & $16(4.8)$ & $271(80.7)$ & $265(77.4)$ & $272(80.46)$ \\
\hline Lower back & $280(83.3)$ & $17(5.1)$ & $15(4.5)$ & $18(5.4)$ \\
\hline Hips/ Thighs & $23(6.8)$ & $73(21.7)$ & $14(20.8)$ & $82(24.4)$ \\
\hline Knee & $103(30.7)$ & $16(4.8)$ & & $16(4.8)$ \\
\hline Ankle/feet & $18(5.4)$ & & & \\
\hline
\end{tabular}

Three hundred and forty one homemakers aged $33.72 \pm 7.45$ years participated in the study. The majority of participants' (54.8\%) educational qualification was below secondary and approximately three-quarter participants' (74\%) monthly income was $\geq 20000$ BDTK. Participants have been working as homemakers for $17.93 \pm 8.11$ years with mean daily activity hours of $8.81 \pm 1.63$. Majority (71.2\%) of the participants was involved in household work with additional activities, and child bearing. Site of the body experienced by pain at least once in life, in the last 12 months, in the last 4 weeks due to household activities $(n=336)$ : In this study, 336 rural homemakers were self-reported individuals with musculoskeletal pain. Their pain experiences at any time of their life span, the last twelve months and the last four weeks were interpreted here (Table 1). On average, lower back pain was complained by a significant portion of participants 272 (80.46\%) throughout the period. This is followed by knee pain $82(24.4)$, neck pain 64(19.13\%), upper back 38(11.3\%), shoulder 18(5.3\%), hips/thighs 18(5.46\%), ankle 16(4.8\%), wrist/hand 15(4.4\%), and elbow/feet 11(3.4\%). (Table1) Due to multiple responses to a question, the number of participants appeared to be slightly higher than the population of the study.

Association between household related factors and musculoskeletal pain in different site of the body in the last 12 months ( $n=336)$ : Chi square test and fisher's exact test were done to find out the association between household related factors and musculoskeletal pain in different site of the body in the last twelve months. A p-value less than 0.05 (typically $\leq 0.05$ ) indicates strong evidence against the null hypothesis, as there is less than a $5 \%$ probability the null is correct. In this study, it is found that lower back pain $(\mathrm{p}<.05)$ has an association with lifting heavy work and awkward position and knee pain $(\mathrm{p}<.05)$ has a relationship with the working hours and awkward position [Table 2]. On the other hand, repetitive work, awkward position and working hours may responsible for wrist pain $(\mathrm{p}<.05)$ (Table 2). Participants who were working for more than 10 years are prone to develop upper back pain $(\mathrm{p}<.05)$ (Table 2)

Table 2: Association between household related factors and musculoskeletal pain in different site of body regions in a given period of 12 months.

\begin{tabular}{|c|c|c|c|c|c|}
\hline \multirow{2}{*}{$\begin{array}{c}\text { Site of pain in last } \mathbf{1 2} \\
\text { months }\end{array}$} & \multicolumn{4}{|c|}{ P value } \\
\cline { 2 - 6 } & $\begin{array}{c}\text { Repetitive } \\
\text { work }\end{array}$ & $\begin{array}{c}\text { Lifting heavy object } \\
(\mathbf{>} \mathbf{k g})\end{array}$ & Awkward position & $\begin{array}{c}\text { Working experience }> \\
\mathbf{1 0} \text { years }\end{array}$ & $\begin{array}{c}\text { Working hours per day }>\mathbf{8} \\
\text { hours }\end{array}$ \\
\hline Neck & $1.0>0.05$ & $1.0>0.05$ & $1.00>0.05$ & $1.0>0.05$ & $1.0>0.05$ \\
\hline Shoulder & $1.00>0.05$ & $1.0>0.05$ & $.615>0.05$ & $.263>0.05$ & $.154>0.05$ \\
\hline
\end{tabular}




\begin{tabular}{|c|c|c|c|c|c|}
\hline Upper back & $.065>0.05$ & $1.0>0.05$ & $1.0>0.05$ & $* .03<0.05$ & $.19>0.05$ \\
\hline Elbow & $.5>0.05$ & $.4>0.05$ & $.3>0.05$ & $1.00>0.05$ & $1.0>0.05$ \\
\hline Wrist/hand & $* .033<0.05$ & $.46>0.05$ & $* .04<0.05$ & $.35>0.05$ & $* .006<0.05$ \\
\hline Lower back & $1.00<0.05$ & $* .003<0.05$ & $* .003<0.05$ & $.46>0.05$ & $1.0>0.05$ \\
\hline Hip/thighs & $1.00<0.05$ & $1.0>0.05$ & $1.0>0.05$ & $.54>0.05$ & $.65>0.05$ \\
\hline Knee & $1.00<0.05$ & $.07>0.05$ & $* .001<0.05$ & $.1>0.05$ & $* .008<0.05$ \\
\hline Ankle/feet's & $.057<0.05$ & $.143>0.05$ & $.52>0.05$ & $.49>0.05$ & $1.0>0.05$ \\
\hline
\end{tabular}

Association between socio-demographic character and musculoskeletal pain in different site of the body in the last 12 months $(\mathrm{n}=336)$ :

Participants were found to have a correlation with their educational level with wrist / hand, lower back, and hip / thigh pain because the p-value here is less than .05 (Table 3). Participants" knee and lower back pain were related to their number of children (Table 3). On the other hand, the age of the respondents acted as an influencer of pain in their wrists / hands and lower back $(\mathrm{p}<.05)$ (Table 3).

Table 3: Association between socio-demographic character and musculoskeletal pain in different site of the body in the last 12 months.

\begin{tabular}{|c|c|c|c|}
\hline \multirow{2}{*}{ Site of pain in last 12 months } & \multicolumn{3}{|c|}{ P value } \\
\cline { 2 - 4 } & Age of the respondent & Educational level & Number of children \\
\hline Neck & $.75>.05$ & $.38>.05$ & $1.0>.05$ \\
\hline Shoulder & $.21>.05$ & $1.00>.05$ & $.48>.05$ \\
\hline Upper back & $.18>.05$ & $.205>.05$ & $.49>.05$ \\
\hline Elbow & $1.00>.05$ & $.417>.05$ & $.37>.05$ \\
\hline Wrist/hand & $.03<.05$ & $* .025<.05$ & $0.12>.05$ \\
\hline Lower back & $* .003<.05$ & $* .03<.05$ & $* .026<.05$ \\
\hline Hip/thighs & $.78>.05$ & $* .002<.05$ & $1.0>.05$ \\
\hline Knee & $.39>.05$ & $.69>.05$ & $.085>.05$ \\
\hline Ankle/feet's & $1.0>.05$ & & $* .007<.05$ \\
\hline
\end{tabular}

Consequences of MSP in different body Region by the respondents $(n=336)$ :

Pie chart shows the distribution of respondents according to the consequences of musculoskeletal pain in last twelve month.
As a result of musculoskeletal pain, most participants (35\%) took medication with or without a prescription, in addition (33\%) met with health professionals, and (26\%) took prevention with or without the advice of health professionals, and (6\%) stopped doing housework (Figure 1).

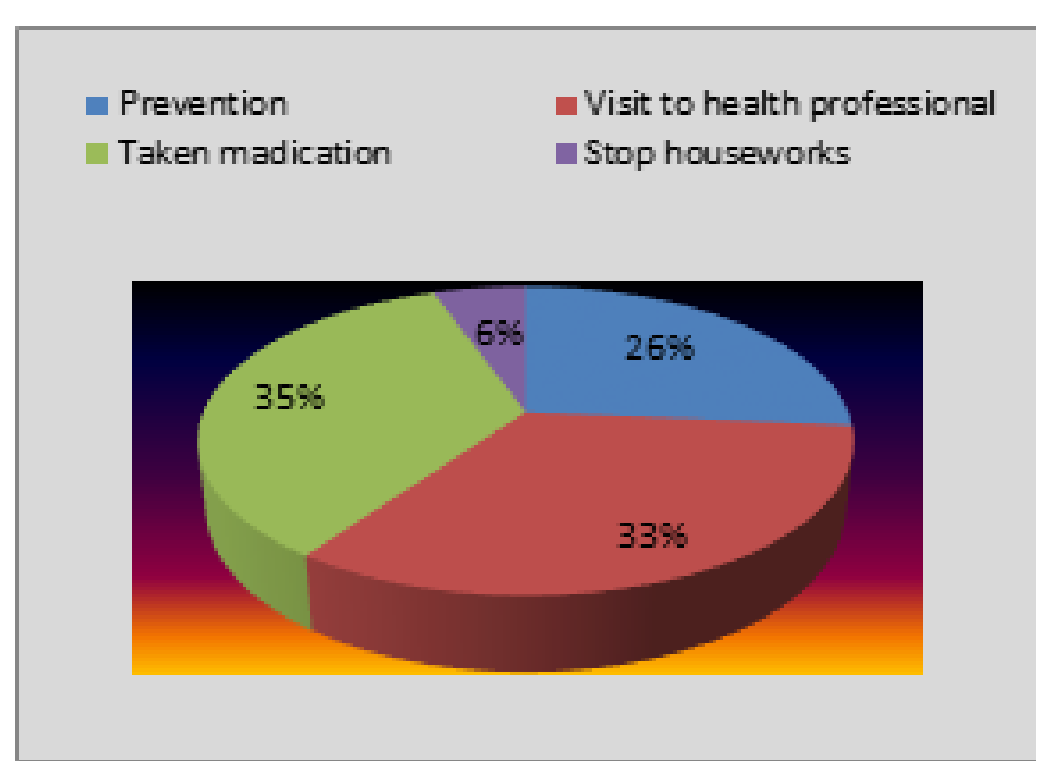

Figure 1: Percentage of consequences of musculoskeletal pain. 
The most sought health seeking behavior among participants was para-professional (54.9\%) followed by professional (54.3\%), unqualified (49.4\%), home remedy (16.6\%) and traditional method (15.4\%) (Table 4). Almost $82.6 \%$ sought treatment on the basis of family advice, while $19.8 \%$ and $5.1 \%$ respectively sought treatment on the basis of low cost and neighbors advice (Table 4). Due to multiple responses to a question, the percentage of participants appeared to be slightly higher than the population of the study.

Table 4: Different types of health care methods and influential factors in its selection.

\begin{tabular}{|c|c|}
\hline Different Types of Health Management Approach & Frequency (\%) \\
\hline Home remedy (Traditional \& Modern form) & $42(16.6)$ \\
\hline Traditional method(Faith-healer, Kabiraj/Hekim, Homeopath) & $39(15.4)$ \\
\hline Unqualified (Drug store salesman) & $125(49.4)$ \\
\hline Para-professional (Village Doctor, Govt. and non-govt.CHW) & $139(54.9)$ \\
\hline Professional (Qualified Allopath doctor, Physiotherapist 7.1\% ) & $139(54.2)$ \\
\hline \multicolumn{2}{|l|}{ Influential factors of choosing health care services } \\
\hline Family advice & $209(82.6)$ \\
\hline Neighbors advice & $13(5.1)$ \\
\hline Low cost & $50(19.8)$ \\
\hline
\end{tabular}

\section{Discussion}

This cross sectional study was carried out to determine the musculoskeletal pain in different anatomical site of the body of rural homemakers as a result of household activities and also identify their health seeking behaviors. The major finding of the study was that the prevalence of musculoskeletal pain was considerably high in almost all of the body regions of the homemakers, with the most reported symptoms were in the lower back, knees, neck, upper back, hips/thighs, wrists/ hands, respectively. This implies that any area of the body can be individually or collectively affected by pain due to indoor activities. On average, $80.46 \%$ suffered from low back pain in last 12 months, whereas $24.4 \%$ for knee and $19.13 \%$ for neck pain. The lowest complaint area was the elbow which was complained by only $3.4 \%$ of participants in the last 12 months. Interestingly, data on lower back pain are very similar to data from two other studies conducted in Bangladesh and India [24, 11]. In addition to this study, several studies [25, 19] have shown that lower back pain is associated with the number of children, age, and educational level, work experience of more than 10 years, awkward postures and weight lifting.

In this study, some household work related factors (total daily hours on household activities, total year of involvement in regular household activities, repetitive work, awkward posture and lifting heavy object) were analyzed to see whether there is any association with the pain in different site of the body during last 12 months. The mirror study of Lebanon reported about women involved in household activities for 46-65 hours per week were 2.5 times more likely to report pain than those who involved in household activities [13]. In parallel, there is significant association between total daily working hours with wrist/ hands and knee pain in this study. Further, the ergonomic risk factors such as repetitive movement were significantly associated with wrist/ hands pain. On the other hand, this study found that more than 10 years of work experience is associated with upper back pain. Further, the awkward position of doing family activities can result in knee and wrist/hand pain. In addition, this study found the relationship between pain and participants' age, educational level, and number of children. Studies conducted in Bangladesh and India support this statement [26, 27]; a research report however showed a zero relationship between MSP and education [10].

To determine a proper intervention plan for the detection and therapy of musculoskeletal pain (MSP) in rural homemakers, their health seeking behavior in this regard was investigated. In this research, taking medication with or without a prescription, visiting health professionals, and taking prevention with or without the advice of health professionals, stopped doing housework have been identified as consequences of MSP. In this present study, 75\% ( $n=253$ ) received treatment for musculoskeletal complaints, in contrast to the treatment-seeking patterns study in Australia 86\% [28]. However, other studies in asian countries namely Indonesia and India showed $73 \%$ and $79 \%$ participants respectively had sought care for it $[20,26]$. The difference may be due to the socio cultural differences in asian and other countries. Further, the number of subjects who received treatment from paraprofessional was higher than the subjects who received treatment from professional allopath doctor in this study. This finding is similar to the results of prior studies of Indonesia [20]. Unlike the findings of a previous study from India [26, 28], the present study found only a few subjects (16.6\%) sought home remedy for pain management. Strangely, most of the respondents (92.9\%) were unaware about physiotherapy treatment for management of pain. Lack of education and availability of physiotherapy professionals and treatment both at the government and private health services settings may be responsible for this condition. In addition, less or nil empowerment or lack of knowledge or a patriarchal social system may compel women to give the opportunity to other family members to choose health-care services for them. Further, participants probably showed a tendency to take affordable treatment due to poverty.

The study is not without limitation. This study used NMQ-E scale to collect information on pain, but working category checklists were not given. Along with this, BMI and psychosomatic pain were not assessed. Furthermore, this study was conducted in only one 
district of Barisal, so the results cannot be generalized to rural domestic workers in the whole of Bangladesh.

\section{Conclusion}

The findings of the study suggest that the common site of pain among the rural homemakers is lower back Many of them go to qualified and un-qualified medical professionals on the basis of family or neighbors' advice or low cost to alleviate their pain. There is the need for appropriate programs and policies to possibly reduce the risk of musculoskeletal pain among this domestic group.

\section{Acknowledgment}

We are gratefully acknowledging the support provided by the National Institute of Preventive and Social Medicine (NIPSOM), Bangladesh.

\section{Conflict of Interest}

The authors of the article declare that there is no interest of conflict with regard to this article.

\section{Disclosure of Benefits}

The authors did not receive any funding for doing this research.

\section{References}

1. Slim ZN, Chaaya M, Habib RR, Arayssi T, Uthma I (2011) High burden of musculoskeletal conditions: A problem that has only recently come to recognition. Chronic Illness 7(4): 311-320.

2. Hossain MD, Aftab A, Al Imam MH, Mahmud I, Chowdhury IA, et al. (2018) Prevalence of work related musculoskeletal disorders (WMSDs) and ergonomic risk assessment among readymade garment workers of Bangladesh: A cross sectional study. PLoS ONE 13(7): 1-18.

3. Özdinç S, Kayabınar E, Özen T, Turan FN, Yilmaz S (2019) Musculoskeletal problems in academicians and related factors in Turkey. J Back Musculoskelet Rehabil 1: 1-7.

4. Wijnhoven HAH, De Vet HCW, Picavet HSJ (2006) Prevalence of musculoskeletal disorders is systematically higher in women than in men. Clinical Journal of Pain 22(8): 717-724.

5. WHO (2018) Reducing The Global Burden Of Musculoskeletal Conditions. World Health Organization.

6. Fong KNK, Law CYT (2008) Self-perceived musculoskeletal complaints: Relationship to time use in women homemakers in Hong Kong. J Occup Rehabil 18(3): 273-281.

7. Habib RR, Hamdan M, Nuwayhid I (2007) Musculoskeletal disorders among full-time homemakers in poor communities. Europe PMC Funders Group 42(2): 1-10.

8. Cardiel MH, Rojas-serrano J (2002) Community based study to estimate prevalence, burden of illness and help seeking behavior in rheumatic diseases in Mexico City . A COPCORD study. Clinical and Experimental Rheumatology 20: 617-624.

9. Efroymson D, Biswas B, Ruma S (2007) The Economic Contribution of Women in Bangladesh through their Unpaid Labor [Internet]. Dhaka: WBB Trust and Health Bridge.

10. Habib MM, Rahman SU (2015) Musculoskeletal symptoms (MSS) and their associations with ergonomic physical risk factors of the women engaging in regular rural household activities: A picture from a rural village in Bangladesh. Work 50(3): 347-356.
11. Gupta G , Nandini N (2015) Prevalence of low back pain in non working rural Housewives of Kanpur, India. Int J Occup Med Environ Health 28(2): 313-320.

12. Hasan MN, Uddin MSG (2016) Women empowerment through health seeking behavior in Bangladesh: Evidence from a national survey. Bangladesh Journals Online (JOL) 6(1): 40-45.

13. Habib RR, Zein KEl, Hojeij S (2012) Hard work at home : musculoskeletal pain among female homemakers. Ergonomics 55(2): 201-211.

14. Frymoyer J (1988) Back Pain and Sciatica. N Engl J Med 318(5): 291-300.

15. IASP (2009) IASP Taxonomy - IASP.

16. Apostoli P, Sala E, Curti S, Cooke RMT, Violante FS, et al. (2012) Loads of housework? Biomechanical assessments of the upper limbs in women performing common household tasks. International Archives of Occupational and Environmental Health 85(4): 421-425.

17. Allaire SH, Meenan RF, Anderson JJ (1991) The impact of rheumatoid arthritis on the household work performance of women. Arthritis Rheum 34(6): 669-678.

18. Leino M, Tuominen S, Pirilä L, Tuominen R (2015) Effects of rheumatoid arthritis on household chores and leisure-time activities. Rheumatol Int 35(11): 1881-1888.

19. Habib RR, Hamdan M ,Nuwayhid I (2006) Musculoskeletal disorders among full-time homemakers in poor communities.Women \& Health 42(2): $1-14$.

20. Andarini S, Arif AZ, Al Rasyid H, Wahono CS, Kalim H et al (2019) Factors associated with health care seeking behavior for musculoskeletal pain in Indonesia: A cross-sectional study. Int J Rheum Dis 22 (7): 1-8.

21. Clewley D , Rhon D , Flynn T, Koppenhaver S, Cook C (2018) Health seeking behavior as a predictor of healthcare utilization in a population of patients with spinal pain. PLoS ONE 13(8): 1-14.

22. Rahman M, Islam MM, Islam MR, Sadhya G, Latif M (2011) Disease pattern and health seeking behavior in rural Bangladesh. Faridpur Medical College Journal 6(1): 32-37.

23. Hoque MM (2019) ABC of research methodology and biostatistics. ( $3^{\text {rd }}$ edn.), Bangladesh medical book seller association, Dhaka, Bangladesh pp: 146-159.

24. Noor IN (2016) Low Back Pain and Disability Status in Rural Housewives. Dissertation. National Institute of Preventive and Social Medicine (NIPSOM) Dhaka: 45-47.

25. Arju A (2018) Pattern of Household Activities and Its Effects on Low Back Pain among Housewives Attended for Physiotherapy Treatment at CRP, Savar. Dissertation. Bangladesh Health Professions Institute (BHPI), University of Dhaka, Bangladesh pp: 1-85.

26. Fazli B, Ansari H, Noorani M, Jafari SM, Sharifpoor Z, et al. (2016) The Prevalence of Musculoskeletal Disorders and its Predictors among Iranians Housewives. International Journal of Epidemiologic Research 3(1): 53-62.

27. Krishnan, A. (2016) Prevalence of musculoskeletal pain and its correlates with ergonomic risk factors among middle aged women home makers in Athiyanoor block Panchayat, Thiruvananthapuram. Dissertation. Sree Chitra Tirunal Institute for Medical Sciences and Technologu, pp: 1-134.

28. Ferreira ML, Machado G, Latimer J, Maher C, Ferreira PH et al (2010) Factors defining care-seeking in low back pain- -a meta-analysis of population based surveys. European Journal of Pain 14(7): 747.e1-7. 